\title{
Effect of Intermittent Versus Continuous Parathyroid Hormone in the Cardiovascular System of Rats
}

\author{
Sanela Smajilovic ${ }^{3}$, Rasmus Schaal-Jensen ${ }^{1,2}$, Reza Jabbari ${ }^{1,2}$, Una Smajilovic ${ }^{1}$, Stig Haunso ${ }^{1,2}$ and \\ Jacob Tfelt-Hansen ${ }^{1,2, *}$ \\ ${ }^{1}$ Laboratory of Molecular Cardiology, Department of Cardiology, Copenhagen University Hospital, Rigshospitalet, \\ Denmark \\ ${ }^{2}$ The Danish National Research Foundation Centre for Cardiac Arrhythmia (DARC), Copenhagen \\ ${ }^{3}$ Department of Medicinal Chemistry, Faculty of Pharmaceutical Sciences, University of Copenhagen, Denmark
}

\begin{abstract}
Objective: PTH increases ionic calcium concentration in the serum, acting primarily on bone and kidney cells through the type $1 \mathrm{PTH}$ receptor. Interestingly, PTH stimulates bone formation when administrated intermittently but causes severe bone loss with continuous administration. Daily injections of PTH are used as the most promising anabolic agent in the treatment of severe osteoporosis. Elevated PTH is reported an independent risk factor for left ventricle hypertrophy.

Design: in rats we investigated the effect of intermittent and continuous administration of PTH on blood pressure, heart rate and development of cardiac hypertrophy and fibrosis.

Results: We did not find PTH to induce heart hypertrophy. In contrast, continuous administration of PTH the mRNA level of a hypertrophic marker gene, atrial natriuretic peptide. When comparing the effect of continuously versus injected PTH collagen 1 mRNA was significantly higher in continuously treated animals.

Conclusion: our data demonstrated a decrease in heart rate upon continuous administration of PTH in rats. No changes in blood pressure were observed. Moreover, neither intermittent nor continuous administration of PTH induced ventricular hypertrophy. But continuous PTH induced a marker of collagen 1. Thus, these data did not reveal any negative effects of the injection of PTH on the cardiovascular system.
\end{abstract}

Keywords: PTH, continuous, intermittently.

\section{INTRODUCTION}

Parathyroid hormone (PTH) is a peptide hormone secreted by the parathyroid glands. PTH is the most important endocrine regulator of short-term calcium homeostasis. Concentration of ionic calcium $\left(\mathrm{Ca}^{2+}\right)$ in extracellular fluid is sensed by the calcium-sensing receptor residing on the surface of the cell membrane of the parathyroid cells. A decrease in $\mathrm{Ca}^{2+}$ induces a release of PTH, whereas an increase in $\mathrm{Ca}^{2+}$ level has an inhibitory effect on the PTH secretion through the calcium-sensing receptor [1-3]. In turn, PTH increases calcium concentration primarily by acting on bone and kidney cells through the type 1 PTH receptor (PTH1R), causing the linning cells of the bones to release calcium into the blood and enhancing the amount of calcium reabsorped along the nephron.

PTH (1-34) is a promising anabolic agent to date in the treatment of osteoporosis [4]. This is due to direct stimulation of bone formation. PTH injections improve bone

*Address correspondence to this author at the Laboratory of Molecular Cardiology, Copenhagen University Hospital, section 9312, Juliane Mariesvej 202100 Copenhagen Ø Denmark; Tel: +45 35456506/61360399; Fax: +45 35456500; E-mail: tfelt@ dadlnet.dk qualities, increase bone mass and prevent osteoporotic fractures. However, the effects of PTH are paradoxical as PTH stimulates bone formation when injected once daily but causes severe bone loss when continuously infused or secreted by the parathyroid glands as in hyperparathyroidism [5].

In addition to the major PTH target organs, the kidney and bone, PTH also has effects on other tissues, including heart and blood vessels [6]. PTH1R is widely expressed throughout the cardiovascular system, including heart [7]. Moreover, mice lacking the PTH1R die prenatally with massive cardiac necrosis, indicating that PTH1R is required for a normal development of the heart [8].

Clinical data indicate that elevated PTH contributes to the progression of several cardiovascular diseases. Patients with end-stage renal diseases, which exhibit elevated plasma concentrations of PTH, develop severe left ventricular hypertrophy. Furthermore, cardiovascular diseases are the leading cause of mortality in end-stage renal disease patients $[9,10]$. Moreover, parathyroidectomy in patients with extremely high serum PTH levels and accelerated left ventricular mass results in a marked reduction of both PTH levels and left ventricular mass $[11,12]$. PTH is also an independent pre- 
dictor of left ventricular mass by high estimated with Mmode echocardiography in males older than 59 years and females younger than 60 years [13]. This effect is only seen when PTH is substantially elevated.

These clinical data are supported by in vitro studies that demonstrate a direct hypertrophic effect of PTH on isolated adult ventricular cardiomyocytes [14]. Moreover, PTH increases beating frequency and $\mathrm{Ca}^{2+}$ influx of cardiomyocytes $[15,16]$.

In this study, we aimed to investigate the effect of intermittent and continuous administration of PTH on blood pressure, heart rate and development of heart hypertrophy and fibrosis in rats.

\section{METHODS}

\subsection{Animal Model}

Male Wistar rats 200-220 g were anesthetized by subcutaneous injection of Hypnorm/ Dormicum for a chronic catheterization procedure. Through the right internal carotid artery, one catheter (medical-grade Tygon tubing) was placed with its tip in the ascending aorta. The catheter was subsequently filled with a solution containing $0.5 \mathrm{ml}$ glucose (500 g/l), heparin (100 IU) and streptokinase (5000 IU) and plugged with a nylon pin. Each catheter was immediately externalized through the neck skin region and secured by a polyester felt disk placed in the subcutis [17].

Following the catheter implantation, the rats were housed

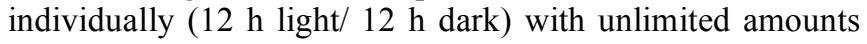
of standard rat chow and tap water. Post-operatively, the rats were allowed to recover for at least 5 days in order to obtain their pre-operative weight.

Before entering the test program both test and control animals base-line blood pressure (BP) were measured using pressure transducers (Baxter Corp) connected to the right arterial catheter. Hart rate (HR) was derived from the arterial pressure signal. Tracings of the variables were displayed on a Watanabe linear recorder (Watanabe Instruments Corp., Japan [17]).

Animals were conscious and unrestrained throughout measurement of BP and HR. After baseline hæmodynamics were measured, PTH (1-34) was administered either continuous or pulsative during 2 weeks. Pulsative administrations were performed once daily (30 $\mu \mathrm{g} / \mathrm{kg} / \mathrm{day})$ or twice daily $(15 \mu \mathrm{g} / \mathrm{kg} /$ day) as a subcutaneous bolus injections of PTH. Continuous administrations were performed using an osmotic minipump (Alza Corp, $200212 \mu \mathrm{l} / \mathrm{d}$ was placed subcutaneously delivering PTH (6 $\mu \mathrm{g} /$ day) or placebo (acetic acid (vehicle)) at a constant rate of $12 \mu \mathrm{l} / \mathrm{d}$ throughout the study period.

At the end of the study period the BP and HR of the animals were measured and recorded. Subsequently, all animals were sacrificed and blood samples were drawn from aorta and analysed on a Ciba Corning $634 \mathrm{Ca}++/ \mathrm{pH}$ Analyzer ${ }^{\circledR}$, ion-selective electrodes to estimate the serum $\mathrm{Ca}^{2+}$ levels (ionic calcium) [18] . Hearts were removed and weighed (total weight, left and right ventricle weight) and snap frozen in liquate nitrogen. The length of the femur was measured before being snap frozen in liquid nitrogen.
All experiments conform with the Guide for the Care and Use of Laboratory Animals published by the US National Institutes of Health NIH publication no. 85-23, revised 1996.

\subsection{Quantification with Real-Time PCR}

Total RNA was isolated from 10-30 mg of heart tissue (left ventricle) with RNeasy Fibrous Tissue Kit (Qiagen) after homogenization with a Mixer Mill 300MM (Retsch, Haan, Germany). RNA purity and concentration were determined by $\mathrm{A}_{260}$ and $\mathrm{A}_{280}$ measurement. First-strand cDNA was synthesised from $1 \mu \mathrm{g}$ of total RNA using Omniscript RT kit (Qiagen).

Quantitative real-time PCR analyses were performed with the Rotor-Gene 3000 (Corbett Research, Mortlake, Australia) and Quantitect SYBR Green PCR Kit (Qiagen) as described previously [19]. The primers were:

GAPDH, forward: 5'- GTC GGT GTG AAC GGA TTT $\mathrm{G}-3^{\prime}$

GAPDH, reverse: 5'- CTT CCC GTG GGT AGA GTC AT -3 ' AG -3

Collagen-I, forward: 5'- AGC TTC ACC CTT AGC ACC

Collagen-I, reverse: 5'- GTG GTA ACG ATG GTG CTG TC $-3^{\prime}$

Collagen-III, forward: 5'- ACC AGG GTC GCC ATT TCT $-3^{\prime}$

Collagen-III, reverse: 5'- GCC TTC TAC ACC TGC TCC TG -3'

Fibronectin, forward: 5'- GTT TTG ACA ACG GGA AGC AT -3'

Fibronectin, reverse: 5'- TCT TCA GGT TCA GGC TTG CT $-3^{\prime}$ 3 ,

ANP, forward: 5'- CCG GTA CCG AAG ATA ACA G-

ANP, reverse: 5'- CTC CAG GAG GGT ATT CAC C-3'

The specificity of each set of primers was ensured by $1.4 \%$ agarose gel analysis and DNA sequence analysis (GATC Biotech, Konstanz, Germany). All mRNAs were quantified in duplicates and the results were normalized to the content of GAPDH within the same sample.

\subsection{Calculations and Statistics}

MAP was estimated, in $\mathrm{mmHg}$, as diastolic pressure plus (systolic minus diastolic pressure) divided by 3 . All data were analyzed with GraphPad Prism using two-tailed unpaired t-test. $\mathrm{P}<0.05$ was considered significant. $\mathrm{n}=$ number of animals

\section{RESULTS}

\subsection{Continuous Administration of PTH}

A continuous infusion of PTH or vehicle was given for a period of 14 days. By end of the treatment, PTH animals were compared to vehicle treated animals (controls). PTH in the mini pumps was released as reflected in the serum ionized calcium level, as serum $\mathrm{Ca}^{2+}$ was significantly higher in 
the PTH treated animals compared with controls $(\mathrm{p}=0.02)$ (Fig. 1a). No significant difference was found in body weight, lung weight, tibia length, or BP (data not shown). Moreover, no visible signs of heart hypertrophy were observed, as measured by the left ventricle mass (Fig. 1b). However, mRNA level of a hypertrophic marker gene, atrial natriuretic peptide (ANP), was significantly increased in the PTH treated animals $(p=0.04)$ (Fig. 2a). No changes in mRNA levels of fibrotic gene markers, collagen 1, collagen 3 and fibronectin were observed (Figs. 2b-d). In the end of the experiment, heart rate tended to be lower in the PTH treated animals (no significance, $\mathrm{p}=0.08$ ) (Fig. 3a). No difference was observed before the experiment (Fig. 3b).

a

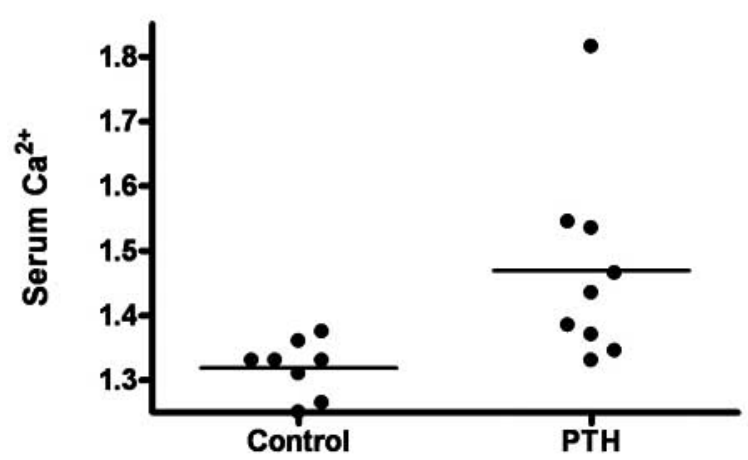

Excluding 2 clear outliers in the control group, the change in the heart rate from baseline to end of the experiment (delta heart rate) was significantly lower in the PTH animals $(\mathrm{p}=0.01)$ (Fig. 3c).

\subsection{Intermittent Administration of PTH}

Animals injected with PTH did not differ in body weight, lung weight or tibia length from animals injected with vehicle (data not shown). Serum $\mathrm{Ca}^{2+}$ tended to be higher in the PTH injected animals, however not significantly (Fig. 4a). No changes in the left ventricle mass or ANP, collagen 3 and fibronectin mRNA levels were observed in the PTH treated

b

Fig. (1). Effect of continuous administration of PTH on: (a) Serum $\mathrm{Ca}^{2+}$ level. (b) Left ventricle mass. Each point represents a value from an individual rat.

a

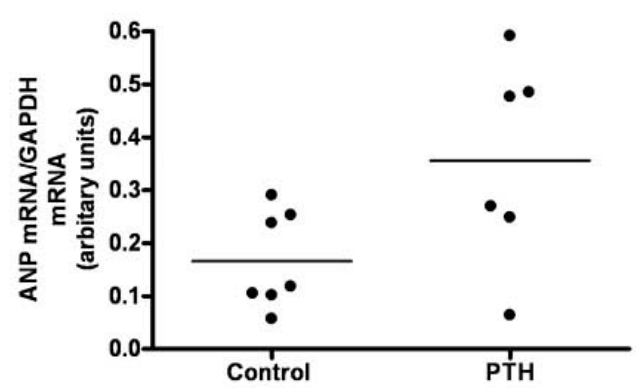

C

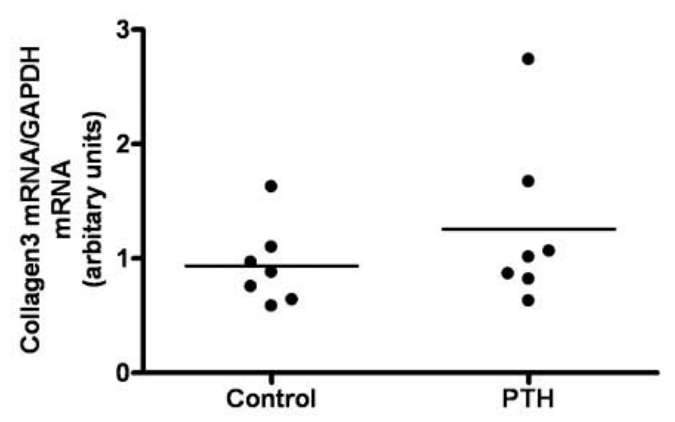

b

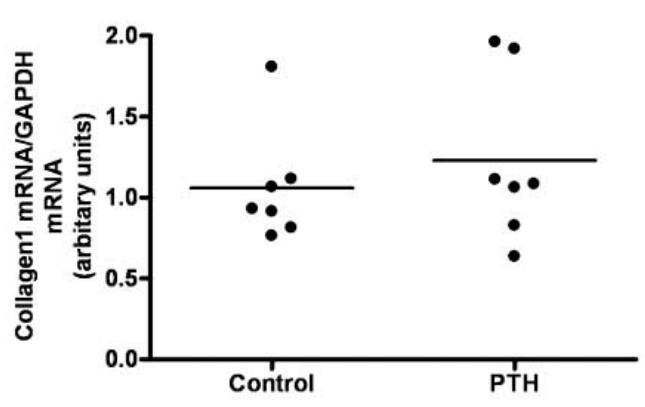

d

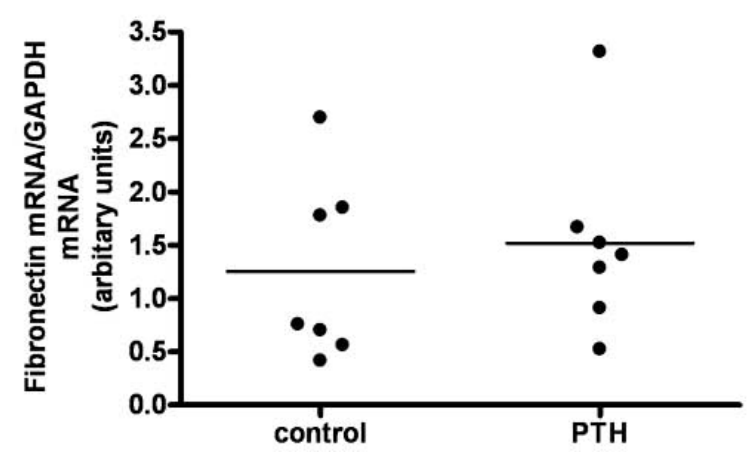

Fig. (2). Left ventricular expression of mRNAs for atrial natriuretic peptide (ANP) (a), Collagen1 (b), Collagen3 (c) and Fibronectin (d) in rats treated with continuous administration of PTH. Each point represents a value from an individual rat. 
group (Figs 4b, 5a, 5c, and 5d). Expression of collagen 1 mRNA tended to be lower in the PTH injected animals, however not significantly (Fig. 5b).

\subsection{Continuous Versus Intermittent Administration of PTH}

We compared animals treated with continuous and intermittent administration of PTH. No significant difference in body weight or left ventricle mass was observed (Figs $6 \mathbf{a}$ and 6b). Serum calcium tended to be higher in animals treated

a

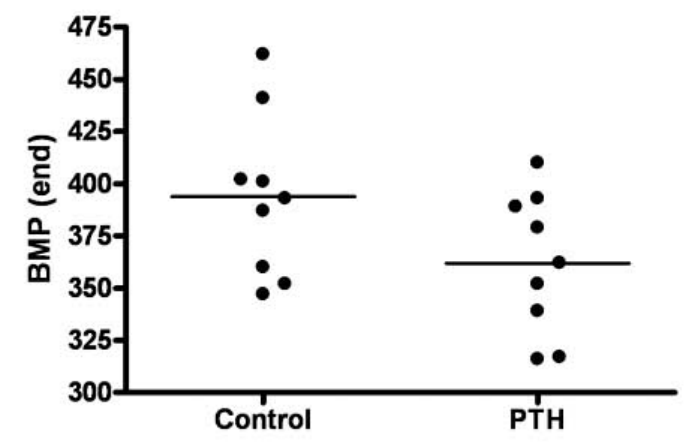

with continuous administration of $\mathrm{PTH}$, however not significantly (Fig. 6c). Moreover, expression of collagen 1 mRNA was significantly higher in continuously treated animals $(\mathrm{p}=0.03)$ (Fig. 7).

\section{DISCUSSION}

PTH is the most important regulator of calcium homeostasis and a key factor in the control of bone modelling. Interestingly, PTH has opposite effects on bone, depending upon the mode of application [5]. Brief daily exposures

b

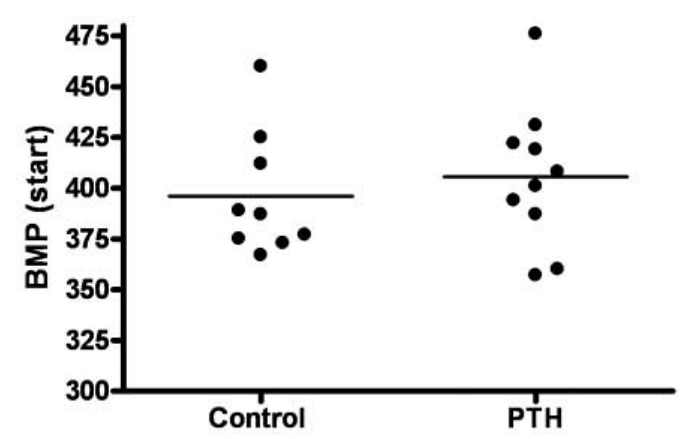

C

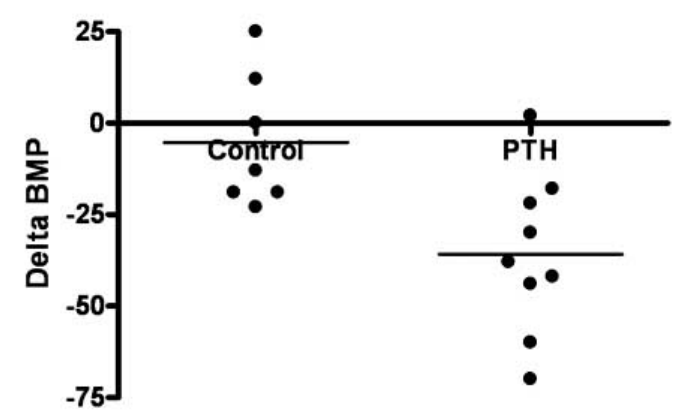

Fig. (3). Effect of continuous administration of PTH on heart rate (BMP). (a) Heart rate by the end of the experiment. (b) Heart rate in the beginning of the experiment. (c) Delta heart rate (excluding 2 outliners from the control group). Each point represents a value from an individual rat.

a

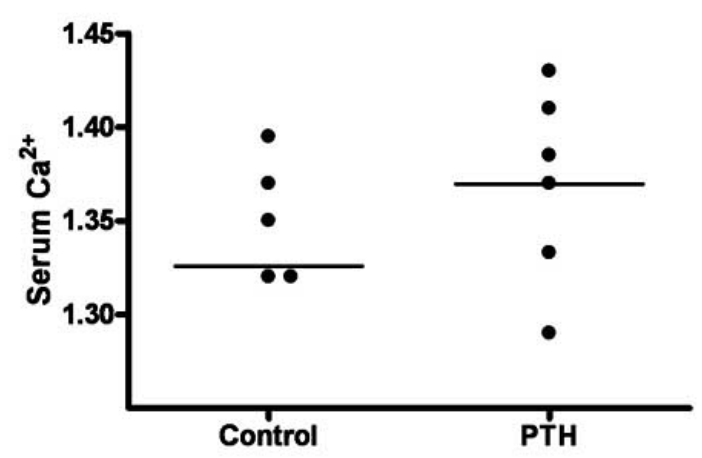

b

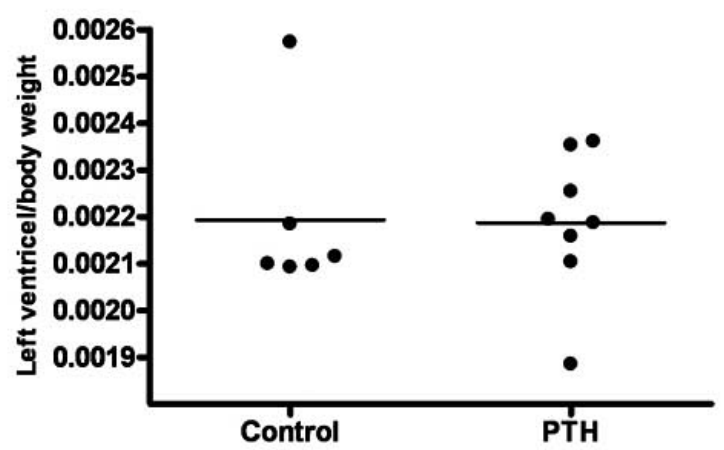

Fig. (4). Effect of intermittent administration of PTH on: (a) Serum $\mathrm{Ca}^{2+}$ level. (b) Left ventricle mass. Each point represents a value from an individual rat. 
a

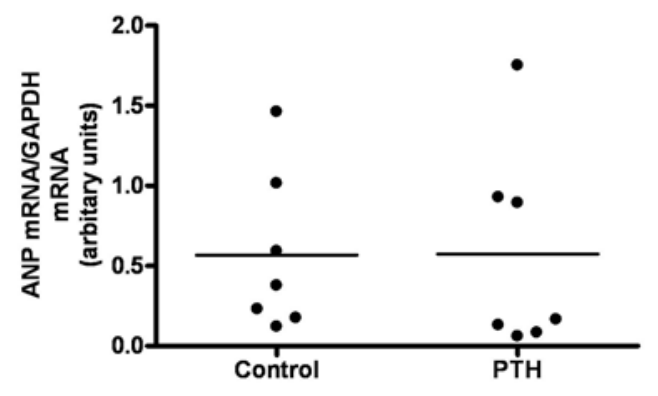

C

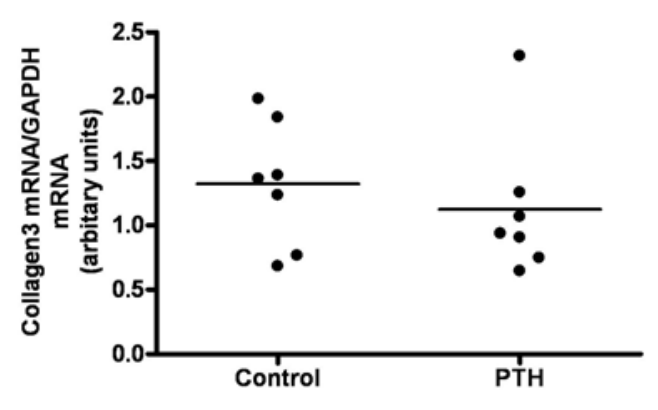

b

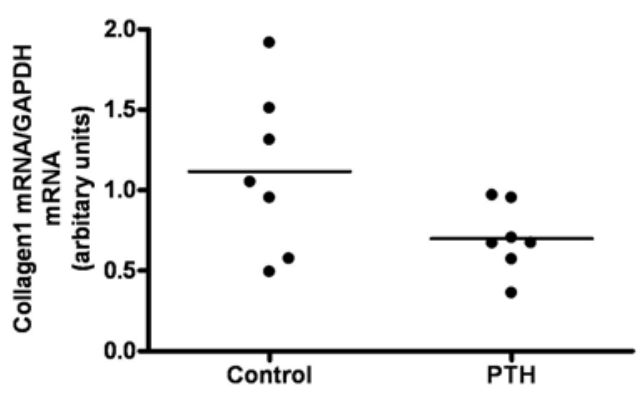

d

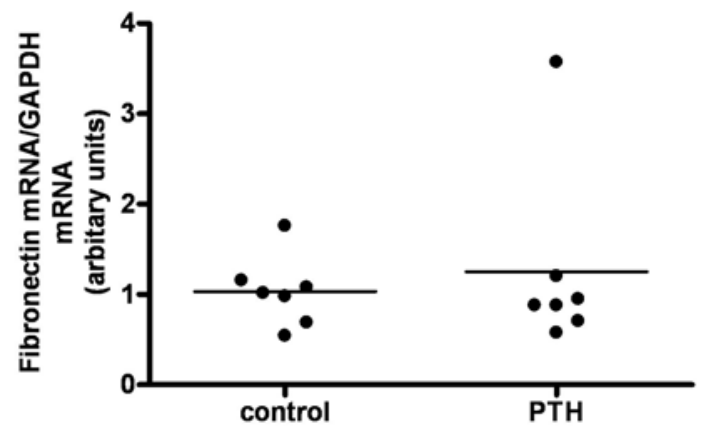

Fig. (5). Left ventricular expression of mRNAs for atrial natriuretic peptide (ANP) (a), Collagen1 (b), Collagen3 (c) and Fibronectin (d) in rats treated with intermittent administration of PTH. Each point represents a value from an individual rat.

a

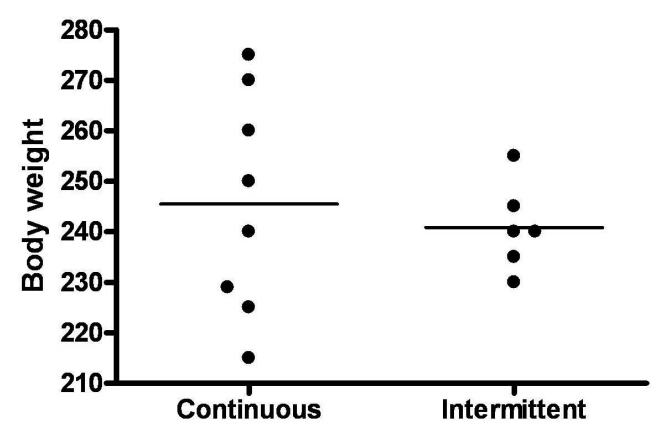

b

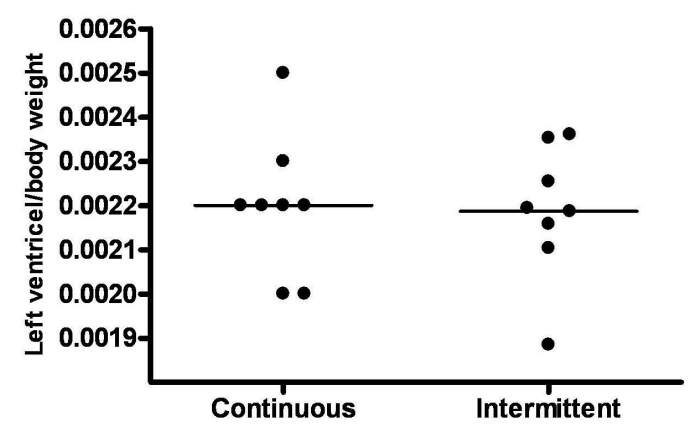

C

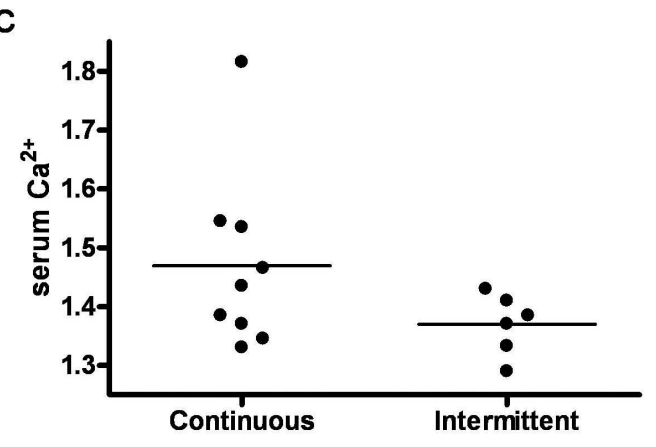

Fig. (6). Effect of continuous versus intermittent administration of PTH on: (a) Body weight. (b) Left ventricle mass. (c) Serum Ca ${ }^{2+}$ level. Each point represents a value from an individual rat. 
result in anabolic effects, while continuously administration at a sustained level has catabolic effects. Daily injections of PTH are used as a novel and promising anabolic treatment for osteoporosis [4].

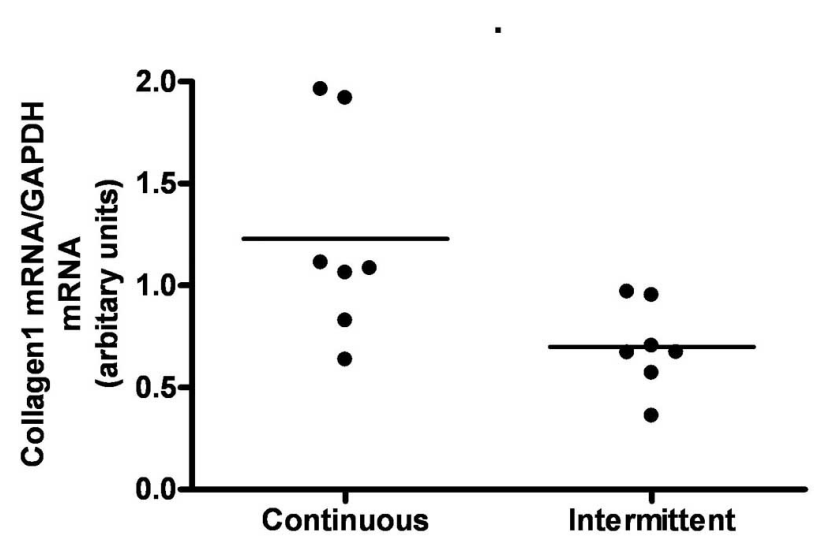

Fig. (7). Effect of continuous versus intermittent administration of PTH on left ventricular expression of mRNA for Collagen1. Each point represents a value from an individual rat.

Although PTH acts primarely on bone and kidney cells, it is well known that cardiovascular cells are target cells for PTH [20]. PTH increases calcium influx in cardiomyocytes but decreases calcium influx in smooth muscle cells [20]. Moreover, PTH exerts a direct hypertrophic effect on cardiomyocytes and increases their beating frequency [1416].

In this study, we examined effects of PTH on BP, heart rate and left ventricle mass in rats.

The effect of PTH on BP is complex. It causes acute vasodilation and lowers BP in rats [21]. However, infusion of human PTH (1-34) in healthy volunteers causes an acute modest increase in BP [22]. Recently, Zaruba et al. observed a decrease in BP after PTH injections in mice [23]. This study did not include a control (vehicle treated) group, and can therefore not exclude that the decrease in BP occurred spontaneously over time and is not an effect of PTH.

It is important to keep in mind the possibility of speciesrelated differences and of different short-term versus longterm BP effects of PTH. Although PTH causes acute decrease in BP in rats, it has been proposed that this acute BPlowering effect might be suppressed in the long run by an elevation of the BP that results from cellular calcium loading [24]. Accordingly, continuous administration of PTH did not have any effect on BP in our study.

PTH has previously been demonstrated to induce an increase in heart rate both in cultured cardiomyocytes $[15,16]$ and in isolated perfused hearts [25]. Moreover, intermittent administration of PTH in rats has also been reported to produce an increase in heart rate [26]. However, in the present study, continuous PTH administration led to a slowing of the heart rate. Interestingly, it has previously been demonstrated that an overexpression of the PTH1R in rats decreases heart rate [27]. The mechanisms underlying this negative chronotropic effect are not clear.

Our data, together with previous studies, suggest that intermittent administration of PTH leads to an acute increase in heart rate, while continuous administration of PTH decreases heart rate.

PTH has previously been demonstrated to directly induce hypertrophy of isolated rat cardiomyocytes [14]. In addition, $70 \%$ of patients with end-stage renal disease, which exhibit elevated plasma PTH levels, suffer from severe left ventricular hypertrophy $[10,28]$. Therefore, we investigated the effect of both intermittent and continuous administration of PTH on left ventricle mass. Neither treatment led to development of hypertrophy in our study, measured by left ventricle mass. However, expression of a hypertrophic marker gene, atrial natriuretic peptide (ANP), was significantly increased in animals treated with continuous administration of PTH compared with controls, suggesting that hypertrophic process appeared to begin. The lack of visible signs of a hypertrophic heart (increase in left ventricle mass) could be caused by a too short exposure compared with the human observations.

We also investigated mRNA expression of fibrotic gene markers, collagen 1, collagen 3 and fibronectin. Neither treatment led to significant changes in expression of the fibrotic gene markers. However, level of collagen 1 mRNA tended to be lower in animals treated with intermittent administration of PTH.

In summary, our data demonstrate, to our knowledge for the first time, a decrease in heart rate upon continuous administration of PTH in rats. No changes in BP were observed. Moreover, neither intermittent nor continuous administration of PTH induced ventricular hypertrophy or a fibrotic process in the timeframe of this study.

\section{ACKNOWLEDGEMENTS}

This work was supported by grants from The Danish National Research Foundation and The John and Birthe Meyer Foundation to J.T.H.; and Copenhagen University to S.S.

\section{REFERENCES}

[1] Smajilovic S, Tfelt-Hansen J. Calcium acts as a first messenger through the calcium-sensing receptor in the cardiovascular system. Cardiovasc Res 2007; 75: 457-67.

[2] Pocotte SL, Ehrenstein G, Fitzpatrick LA. Regulation of parathyroid hormone secretion. Endocr Rev 1991; 12: 291-301.

[3] Tfelt-Hansen J, Schwarz P, Brown EM, Chattopadhyay N. The calcium-sensing receptor in human disease. Front Biosci 2003; 8: s377-90.

[4] Girotra M, Rubin MR, Bilezikian JP. The use of parathyroid hormone in the treatment of osteoporosis. Rev Endocr Metab Disord 2006; 7: 113-21.

[5] Poole KE, Reeve J. Parathyroid hormone - a bone anabolic and catabolic agent. Curr Opin Pharmacol 2005; 5: 612-7.

[6] Bro S, Olgaard K. Effects of excess PTH on nonclassical target organs. Am J Kidney Dis 1997; 30: 606-20.

[7] Urena P, Kong XF, Abou-Samra AB, et al. Parathyroid hormone $(\mathrm{PTH}) / \mathrm{PTH}$-related peptide receptor messenger ribonucleic acids are widely distributed in rat tissues. Endocrinology 1993; 133: 61723.

[8] Qian J, Colbert MC, Witte D, et al. Midgestational lethality in mice lacking the parathyroid hormone (PTH)/PTH-related peptide receptor is associated with abrupt cardiomyocyte death. Endocrinology 2003; 144: 1053-61.

[9] Bernardi D, Bernini L, Cini G, et al. Asymmetric septal hypertrophy in uremic-normotensive patients on regular hemodialysis. An 
M-mode and two-dimensional echocardiographic study. Nephron 1985; 39: 30-5.

[10] London GM, De Vernejoul MC, Fabiani F, et al. Secondary hyperparathyroidism and cardiac hypertrophy in hemodialysis patients. Kidney Int 1987; 32: 900-7.

[11] Sato S, Ohta M, Kawaguchi Y, et al. Effects of parathyroidectomy on left ventricular mass in patients with hyperparathyroidism. Miner Electrolyte Metab 1995; 21: 67-71.

[12] Hara S, Ubara Y, Arizono K, et al. Relation between parathyroid hormone and cardiac function in long-term hemodialysis patients. Miner Electrolyte Metab 1995; 21: 72-6.

[13] Saleh FN, Schirmer H, Sundsfjord J, Jorde R. Parathyroid hormone and left ventricular hypertrophy. Eur Heart J 2003; 24: 2054-60.

[14] Schluter KD, Piper HM. Trophic effects of catecholamines and parathyroid hormone on adult ventricular cardiomyocytes. Am J Physiol 1992; 263: H1739-46.

[15] Bogin E, Massry SG, Harary I. Effect of parathyroid hormone on rat heart cells. J Clin Invest 1981; 67: 1215-27.

[16] Bogin E, Harary I. The relationship of calcium and parathyroid hormone in their effect on heart cells. Mol Cell Biochem 1987; 77: 29-35.

[17] Laursen JB, Mulsch A, Boesgaard S, et al. In vivo nitrate tolerance is not associated with reduced bioconversion of nitroglycerin to nitric oxide. Circulation 1996; 94: 2241-7.

[18] Tfelt-Hansen J, Schwarz P, Torring O. Rapid suppression of S-PTH by oral calcitriol and calcium in healthy premenopausal women. Scand J Clin Lab Invest 2001; 61: 395-400.

[19] Tfelt-Hansen J, Schwarz P, Terwilliger EF, Brown EM, Chattopadhyay N. Calcium-sensing receptor induces messenger ribonucleic acid of human securin, pituitary tumor transforming gene, in rat testicular cancer. Endocrinology 2003; 144: 5188-93.
[20] Schluter KD, Piper HM. Cardiovascular actions of parathyroid hormone and parathyroid hormone-related peptide. Cardiovasc Res 1998; 37: 34-41.

[21] Pang PK, Tenner TE, Jr., Yee JA, Yang M, Janssen HF. Hypotensive action of parathyroid hormone preparations on rats and dogs. Proc Natl Acad Sci USA 1980; 77: 675-8.

[22] Fliser D, Franek E, Fode P, et al. Subacute infusion of physiological doses of parathyroid hormone raises blood pressure in humans. Nephrol Dial Transplant 1997; 12: 933-8.

[23] Zaruba MM, Huber BC, Brunner S, et al. Parathyroid hormone treatment after myocardial infarction promotes cardiac repair by enhanced neovascularization and cell survival. Cardiovasc Res 2008; 77: 722-31.

[24] Ogata H, Ritz E, Odoni G, Amann K, Orth SR. Beneficial effects of calcimimetics on progression of renal failure and cardiovascular risk factors. J Am Soc Nephrol 2003; 14: 959-67.

[25] Shimoyama M, Ogino K, Furuse Y, et al. Signaling pathway and chronotropic action of parathyroid hormone in isolated perfused rat heart. J Cardiovasc Pharmacol 2001; 38: 491-9.

[26] DiPette DJ, Christenson W, Nickols MA, Nickols GA. Cardiovascular responsiveness to parathyroid hormone (PTH) and PTHrelated protein in genetic hypertension. Endocrinology 1992; 130: 2045-51.

[27] Fritsch S, Lindner V, Welsch S, et al. Intravenous delivery of $\mathrm{PTH} / \mathrm{PTHrP}$ type 1 receptor cDNA to rats decreases heart rate, blood pressure, renal tone, renin angiotensin system, and stressinduced cardiovascular responses. J Am Soc Nephrol 2004; 15: 2588-600.

[28] Bernardi D, Bernini L, Cini G, Ghione S, Bonechi I. Asymmetric septal hypertrophy and sympathetic overactivity in normotensive hemodialyzed patients. Am Heart J 1985; 109: 539-45.

This is an open access article licensed under the terms of the Creative Commons Attribution Non-Commercial License (http://creativecommons.org/licenses/ by-nc/3.0/) which permits unrestricted, non-commercial use, distribution and reproduction in any medium, provided the work is properly cited. 